\title{
Dialogismo y prácticas apropiacionistas en el videoarte contemporáneo
}

\section{Javier Moral Martín ${ }^{1}$ \\ Fernando Canet $^{2}$}

Recibido: 2017-07-04

Enviado a pares: 2017-07-12
Aprobado por pares: 2017-09-06

Aceptado: 2017-10-10

DOI: 10.5294/pacla.2018.21.4.9

Para citar este artículo / to reference this article / para citar este artigo

Moral, J. y Canet, F. (2018). Dialogismo y prácticas apropiacionistas en el videoarte contemporáneo. Palabra Clave, 21(4), 1164-1188. doi: 10.5294/pacla.2018.21.4.9

\section{Resumen}

El principal objetivo de este trabajo consiste en evaluar dos de las más importantes dinámicas de interpelación crítica que operan en el ámbito del videoarte contemporáneo: el found footage y el remake. Para ello, se ponen en relación el concepto de dialogismo con la noción de apropiacionismo, y se confrontan con las dinámicas artísticas de resignificación iniciadas con las vanguardias históricas. En ese sentido, desde que el arte de principios del siglo XX comenzara a trabajar con materiales que ya circulaban en la sociedad, la migración de las imágenes de un medio a otro se ha convertido en una dominante del sistema artístico actual. Y más que la publicidad o la televisión, el discurso artístico ha utilizado como interlocutor privilegiado a la imagen cinematográfica. Por un lado, se encuentran aquellos creadores que se han apropiado en sentido literal del material cinematográfico para deconstruirlo en una nueva unidad que recompone el conjunto de partida (de Joseph Cornell a Douglas Gordon pasando por Bruce Conner). Por otro lado, están aquellos artistas que han dialogado con la imagen cinematográfica desde el exterior: las propuestas de Mark Lewis, Pierre Huygue o Deimantas Narkevičius obligan a una reflexión audiovisual que cuestiona

1 orcid.org/0000-0001-5498-4883. Universidad Politécnica de Valencia, España. framomar@har.upv.es

2 orcid.org/0000-0002-1455-9249. Universidad Politécnica de Valencia, España. fercacen@upv.es 
los conceptos de originalidad y copia, elementos esenciales tanto del devenir estético como de la experiencia estética referida a un sujeto. En ambos casos, no obstante, puede llegarse a una misma conclusión: si la imagen artística contemporánea se caracteriza por su condición fantasmal y errante, es el espíritu cinematográfico lo que parece animarla.

\section{Palabras clave}

Videoarte, metraje encontrado, apropiacionismo, remake, ready-mades, found footage (Fuente: Tesauro de la Unesco). 


\section{Dialogism and Appropriationist Practices in Contemporary Video Art}

\section{Abstract}

The main objective of this work is to evaluate two of the most important aspects of critical interpellation that operate in the field of contemporary video art: found footage and remakes. To do so, the authors relate the concept of dialogism to the notion of appropriationism, and look at them in light of the artistic dynamics of resignification initiated with the avant-garde movements of the past. In that respect, ever since the art of the early XX century began to work with materials that were already circulating in society, the migration of images from one medium to another has become a dominant feature of the current artistic system. And, more than advertising or television, the artistic discourse has used the cinematographic image as a privileged interlocutor. On the one hand, there are those creators who have appropriated cinematographic material in a literal sense, in order to deconstruct it into a new unit that recomposes the starting set (from Joseph Cornell to Douglas Gordon through Bruce Conner). On the other hand, there are those artists who have disscused with the cinematographic image from the outside: the proposals of Mark Lewis, Pierre Huygue or Deimantas Narkevičius demand audiovisual reflection that questions the concepts of originality and copy, essential elements of both aesthetic transformation, as well as the aesthetic experience referred to a subject. However, the same conclusion can be reached in both cases: if the contemporary artistic image is characterized by its ethereal and roving condition, it is the cinematic spirit that seems to animate it.

\section{Keywords}

Video art; footage found; appropriationism; remake; ready-mades; found footage (Source: Unesco Thesaurus). 


\section{Dialogismo e práticas apropriacionistas na videoarte contemporânea}

\section{Resumo}

O principal objetivo deste trabalho consiste em avaliar duas das mais importantes dinâmicas de interpelação crítica que operam no âmbito da videoarte contemporânea: a técnica narrativa found footage e o remake. Para isso, relacionam-se o conceito de dialogismo com a noção de apropriacionismo, e confrontam-se com as dinâmicas artísticas de ressignificação iniciadas com as vanguardas históricas. Nesse sentido, desde que a arte do início do século XX começou a trabalhar com materiais que já circulavam na sociedade, a migração das imagens de um meio a outro tem se tornado uma dominante do sistema artístico atual. E, mais que a publicidade ou a televisão, o discurso artístico vem utilizando como interlocutor privilegiado a imagem cinematográfica. Por um lado, encontram-se aqueles criadores que têm se apropriado em sentido literal do material cinematográfico para desconstruí-lo numa nova unidade que recompõe o conjunto de partida (de Joseph Cornell a Douglas Gordon passando por Bruce Conner). Por outro, estão aqueles artistas que têm dialogado com a imagem cinematográfica a partir do exterior: as propostas de Mark Lewis, Pierre Huygue ou Deimantas Narkevičius obrigam a uma reflexão audiovisual que questiona os conceitos de originalidade e cópia, elementos essenciais tanto do devir estético quanto da experiência estética referida a um sujeito. Em ambos os casos, contudo, pode chegar-se a uma mesma conclusão: se a imagem artística contemporânea se caracteriza por sua condição fantasmal e errante, é o espírito cinematográfico o que parece animá-la.

\section{Palavras-chave}

Videoarte, metragem encontrado, apropriacionismo, remake, ready-mades, found footage (Fonte: Tesauro da Unesco). 


\section{Introducción}

La migración de formas y contenidos audiovisuales en el arte actual se perfila como uno de los fenómenos más activos de nuestro universo estético. El tradicional anclaje de la imagen en un soporte que le otorgaba su condición aurática — aquella imagen materia que según José Luis Brea (2014) actuó como modelo estético de la historia de la representación durante siglos -3 ha dado paso a la ubicuidad en la era de la e-imagen: en nuestra realidad multiplataforma, las imágenes se caracterizan por su carácter evanescente, pura presencia que muta y se permuta con extrema desenvoltura. Favorecida por el doble signo de la digitalización y la desmaterialización de la obra de arte, la presencia de una imagen en un medio adquiere ahora un estado temporal: guarda en su memoria el lugar de procedencia a la vez que se proyecta al lugar donde migrará.

En este estado de cosas, llama poderosamente la atención la centralidad de la imagen cinematográfica en el discurso artístico contemporáneo. Si resulta lógico que, en cuanto práctica significante central del universo audiovisual del siglo XX, el cine despertara el interés del arte y los artistas, menos debería serlo hoy a tenor de su posición subsidiaria. Sin embargo, a pesar de su relegación a los márgenes por otras realidades virtuales (videojuegos, series televisivas, relatos audiovisuales en la web, etc.), el cine sigue manteniéndose como el interlocutor privilegiado del arte.

Así pues, en este trabajo, se evaluarán dos de las más importantes dinámicas de interpelación crítica que operan en el ámbito del videoarte: el found footage y el remake. Para ello, se pondrán en relación la noción de dialogismo desarrollada por el teórico ruso Mijail Bajtin (1987, 1989), por el que un texto se convierte en "objeto de representación" de otro, con el concepto de apropiacionismo, que ha tenido un especial desarrollo artístico desde la década de 1980, y que se caracteriza por la resignificación que opera una imagen a partir de otra imagen referente (Kuspit, 1993, Prada, 2001; Welchman, 2003; Evans, 2009).

3 Imagen materia: "Imagen producida como — inscrita — en su soporte, soldada a él, indisolublemente apegada a su forma materializada bajo este régimen técnico, la imagen tiene que ocurrir sustanciada en objeto: —cuadro, grabado, dibujo, bajo-relieve, escultura - del que resulta inseparable, en el que se encuentra incrustada, sin el cual no puede darse" (Brea, 2014, p. 11). 


\section{Primeros interlocutores: de la publicidad a la televisión}

\section{Primeras vanguardias}

El proceso de migración de las imágenes y su correlato artístico, la apropiación, es consustancial a la retórica vanguardista, como recordó Nicolas Bourriaud (2009). Marcel Duchamp se perfila como emblema de aquel artista que no trabaja con materias primas, sino "con objetos que ya están circulando en el mercado cultural" (p. 8), de tal manera que sus ready-mades no pretenden elaborar nuevas formas artísticas, sino insertar "un objeto en un nuevo escenario, considerarlo como un personaje dentro de un relato" (p. 25). En ese sentido, sus conocidas piezas In Advance of the Broken Arm (1915) o Fountain (1917) implican el cambio de sentido del objeto tridimensional mediante una elección del artista que transforma su función original. Otras, sin embargo, como Apolinère Enameled (1916-1917) — homenaje a Guillaume Apollinaire a partir de la manipulación de la imagen publicitaria de la conocida marca de pinturas Sapolin Enamel - o L.H.O.O.Q. (1919) - explícita afrenta al fetiche cultural que representa La Gioconda, de Leonardo da Vinci - implican la generación de una nueva imagen a partir de otra preexistente. En ambos casos, el juego especular sirve al artista como elemento de cuestionamiento crítico y reflexividad teórica.

No obstante, la diferencia entre los primeros ejemplos y los segundos deviene esencial: si In Advance of the Broken Arm y Fountain activan en el espectador una experiencia estética que gira alrededor del mismo objeto en virtud de una descontextualización que afecta su significado, Sapolin Enamel y L.H.O.O.Q. necesitan, por el contrario, del concurso de otro objeto, de otra imagen previa, que permita clausurar desde el exterior esta experiencia estética. Objetos circulantes en el mercado cultural, estos últimos ready-mades nos permiten vislumbrar uno de los primeros referentes de apropiación por parte de los movimientos de las vanguardias históricas: ${ }^{4}$

4 Desde el planteamiento aquí esgrimido, la "integración" de elementos reales en el cuadro que operaron los cubistas con Picasso a la cabeza (con ejemplos como Bottle of Vieux Marc, Glass, Guitar and Newspaper, 1913) poco tiene que ver con el cuestionamiento de los valores culturales planteado por Duchamp y los dadaístas. Antes bien, se criticaba 
la publicidad se erigió en el principal referente al que se asomó el arte en las primeras décadas del siglo XX. El espíritu antiburgués y la tentativa de impugnación de la institución arte que plantearon el dadá y el surrealismo se sirvieron del imaginario publicitario de finales del siglo XIX y comienzos del siglo XX para desviar los mensajes vehiculados por una sociedad capitalista en plena ebullición. En este contexto, el collage y el fotomontaje fueron los principales aliados en la batalla de la mano de artistas, como Kurt Schwitters, Man Ray, George Grosz, John Heartfield, Raoul Hausmann o Hanna Höch.

\section{Segundas vanguardias}

Pero fue con la llegada de la imagen electrónica cuando los artistas se apropiaron ampliamente de los medios de comunicación como discurso objeto para sus intereses estéticos y críticos. Que todo cambiara con la aparición del video en la década de 1960 tuvo tanto que ver con la aparición de una nueva tecnología de uso más asequible como con un auténtico cambio del régimen estético. Como han señalado, entre otros, Simon Marchán Fiz (1994) o Laura Baigorri (2004), la experimentación multidisciplinar y confrontación artística con otros medios durante este periodo fue consecuencia en gran medida del desbordamiento de la esfera estética sobre el resto de esferas sociales, por un lado, y de la desjerarquización de las prácticas culturales, por otro.

En este nuevo escenario (auténtica constitución de una nueva formación discursiva en el sentido expuesto por Michel Foucault), ${ }^{5}$ la imagen videográfica parece haber necesitado casi desde el principio otros medios con los que confrontar su identidad; de manera especial la televisión: nu-

el principio trompe l'oeil que había guiado la pintura desde el Renacimiento. El clásico libro de Peter Bürger, Teoría de la vanguardia (1997), continúa siendo un referente esencial en la comprensión de las vanguardias históricas.

5 Concepto nodal en La arqueología del saber, tiene su formulación preliminar en Respuesta al círculo de epistemología. Para Michel Foucault, las formaciones discursivas se designarían, no tanto por su fijación en un objeto definido y clausurado, sino como por una serie de relaciones de coexistencia situadas en niveles diversos que garantizan su unidad (histórica y por tanto transitoria): los objetos que construye desde luego, pero también ciertas especificidades en su formulación enunciativa (de tipo estilístico), redes teóricas que actuarían como "esquemas formadores de conceptos", y un "campo de posibilidades estratégicas" referido a la distribución de posiciones dispuestas y previstas por el propio campo discursivo (Buguelin, 1970, pp. 221-270). 
merosos artistas se aproximaron al universo icónico y temático de la pequeña pantalla durante la década de $1960 .^{6}$

Los dos ejes que vertebraron el comienzo del videoarte y su relación con la televisión están claramente definidos en estas obras inaugurales. Por un lado, la experimentación electromagnética de la imagen y sus posibilidades plásticas y figurativas. Por otro, y de manera más determinante incluso, la apropiación y el cuestionamiento del discurso televisivo como vehículo de expresión de la ideología dominante. No en vano el détournement del material audiovisual de la pequeña pantalla permitía desenmascarar el falso lenguaje del espectáculo capitalista y mostrar su verdadero rostro alienante a través de la ironía y un montaje sumamente vehemente.

Esta segunda vertiente, que encontró en el letrismo primero - $-\mathrm{y}$ en el situacionismo después - sus principales sustentos teóricos, se ha expandido bajo formas tan diversas como los mashups, scratch videos o el VJing, gracias a la trayectoria de artistas como Bruce Conner y obras como Report (1963-1967) o Television Assassination (1975), los colectivos Ant Farm (conformado por Chip Lord y Doug Michels) y Guerrilla TV durante la década de 1970 (conformado por los artistas Paul Ryan, Frank Gillete y Michael Shamberg), el propio Nam June Paik o — ya dentro de nuestra más cercana contemporaneidad - el trabajo de artistas como Omer Fast. Así, en su obra CNN Concatenated (2002), Omer Fast generó una base de datos de 10000 palabras extraídas de grabaciones de locutores y comentaristas de la conocida cadena de televisión durante 2001 y 2002. Posteriormente, este artista israelí reorganizó los fragmentos de dicha base de datos en varios monólogos que se alejan del tono informativo de origen para acercarlo a una valoración emotiva dirigida al espectador. En un vertiginoso collage en el que mudan las figuras y en el que solo la banda sonora conserva la continuidad, se suceden durante $18 \mathrm{~min}$ los conocidos rostros de los presentadores de los noticiarios de la $\mathrm{CNN}$.

6 Los principales hitos son la exposición del coreano Nam June Paik en la Galería Parnass de Wuppertal en marzo de 1963 (la Exposition of Music-Electronic Television en la que presentó trece televisores manipulados electrónicamente que emitían imágenes abstractas) y algunos meses más tarde el happening que Wolf Vostell realizó en una galería de Nueva York, donde enterró un televisor encendido atado con un alambre de púas. 


\section{Segundo interlocutor: el cine}

\section{Primeras vanguardias}

No obstante, si existe un medio que continúa actuando como interlocutor privilegiado del arte, ese es sin duda el cine. Casi desde su aparición, y una vez que la intelectualidad abandonó una primera infravaloración del nuevo medio, los artistas se aproximaron al cine desde planteamientos muy dispares: del acercamiento puramente lúdico (véanse las preliminares querencias surrealistas por los films seriales como comedias y westerns de la segunda mitad de la década de 1910) ${ }^{7}$ a la búsqueda en el nuevo medio de aquello que resultaba inalcanzable para la pintura (el movimiento de la imagen).

En lo que concierne al estado dispersivo de las imágenes que rige nuestra contemporaneidad, tienen especial interés aquellos artistas que, en el contexto de las vanguardias históricas, se asomaron al cine, no como base material y plástico (la manipulación de la "película fotosensible", como hicieron Léopold Survage, Viking Eggeling o Walter Ruttmann), ${ }^{8}$ sino como forma de asimilación estética; en algunos casos, incluyendo el film explícitamente en su tejido material, en otros utilizándolo como estructura narrativa y temática a partir de la cual expandir sus potencialidades discursivas.

En ese sentido, puede afirmarse que, si el aliento crítico del dadaísmo se nutrió del imaginario de la publicidad, la mitomanía inherente al surrealismo terminó por empujarlo hacia el cine. $\mathrm{Al}$ respecto, no puede dejar de anotarse Rose Hobart (1936), de Joseph Cornell, artista neoyorkino cuyo trabajo se nutre de la práctica del collage y el coleccionismo. Próximo a la órbita de Marcel Duchamp, Cornell se apropió de East of Borneo (George Melford, 1931) para construir un peculiar objeto a medio camino del fetiche onanista y la perturbación delirante. La premisa es extremadamente sencilla, pero el resultado es a todas luces fascinante. A partir del film de aventuras de Melford, el artista recortó el metraje y empalmó solo las escenas en las que aparece su protagonista, Rose Hobart. La drástica evacuación

\footnotetext{
7 Para una profundización en las costumbres espectatoriales surrealistas, puede consultarse Monterde (1991, pp. 49-79).

$8 \mathrm{Al}$ respecto, pueden revisarse la clásica Historia del cine experimental, de Jean Mitry (1974), o el más reciente trabajo del profesor Sánchez-Biosca (2004).
} 
de todos aquellos fragmentos que permiten la sutura del hilo narrativo del film, el virado a azul del metraje y su ralentización al ritmo de la proyección del cine mudo, así como la elisión de la banda sonora original y su sustitución por el acompañamiento musical de dos canciones del álbum Holiday in Brazil del compositor Nestor Amaral, genera un discurso errante y disperso, de fuerte carga onírica, en el que el goce visual del espectador se origina, precisamente, en la absoluta negación del relato. Pura imagen que se ofrece a la mirada sin una sintagmática que permita su identificación con el originario relato de aventuras.

\section{Segundas vanguardias}

Considerado por diversos autores como el origen de esa categoría tan fecunda como compleja - el cine de found footage o cine de metraje encontrado- (Wess, 1993; Bonet, 1993; Weinrichter, 1998, 2009; Arthur, 1999, Zryd, 2003; Elsaesser, 2015), ${ }^{9}$ la senda abierta por Rose Hobart ha sido profusamente transitada en la segunda mitad del siglo XX. Muchos han sido los creadores que han utilizado la imagen fílmica como material estético y discursivo desde ese momento, comenzando por Bruce Conner, nombre propio del movimiento underground norteamericano, y su celebrada AMOVIE (1958). Considerada como una de las obras centrales del apropiacionismo cinematográfico, a través de un montaje minucioso de imágenes de procedencia heterogénea, Conner logra asociaciones semánticas inesperadas. Esta obra tuvo su continuación en la década siguiente con autores como Ken Jacobs, también neoyorkino, y piezas como Tom, Tom the Piper Son (Ken Jacobs, 1969 y 1971), cuyas dos versiones se apropian de un film homónimo de 10 min realizado por G. W. "Billy" Bitzer en 1905. Con esta propuesta, el artista desgrana los mecanismos icónicos del devenir narrativo del relato original. Así, la exhaustiva argumentación de Noël Burch en El tragaluz del infinito (1987) sobre un modo de representación primitivo es corroborada fehacientemente en el film ensayo de Jacobs. La minuciosa disección operada sobre los tableaux del film original, el persistente reencuadre que intenta ordenar una imagen que se presenta al espectador en bruto, sin je-

9 No obstante, otros autores sitúan los orígenes del cine de found footage en piezas como La caída de la dinastía Romanov (Esfir Shub, 1927), en L'Histoire du soldat inconnu (Henri Storck, 1931), e incluso, en Crossing the Great Sagrada (Adrian Brunel, 1924). 
rarquizar, adquiere un llamativo valor didáctico que pone en evidencia los modelos representativos fílmicos de comienzos del siglo.

\section{Found footage y posmodernidad}

Pero fue, sobre todo, a partir de la década de 1990, como recordó Nicolas Bourriaud (2002), cuando se dejaron sentir con mayor intensidad los proyectos artísticos que se apropiaban del universo cinematográfico como materia formal. No en vano las exposiciones dedicadas a valorar esta tendencia fueron numerosas durante este periodo, ${ }^{10}$ caso de Art and Film Since 1945: Hall of Mirrors (Museum of Contemporary Art en Los Angeles, 1996), Scream and Scream Again: Film in Art (Museum of Modern Art de Oxford, 1996), Cinéma Cinéma, Contemporary Art and the Cinematic Experience (Stedelijk Van Abbemuseum de Eindhoven, 1999), Notorious: Alfred Hichcock and Contemporary Art (Museum of Modern Art de Oxford, 1999) o - ya en la siguiente década-Remakes (CAPC musée d'art contemporain de Bordeaux, 2003, DA2 de Salamanca, 2004) o Found Footage: Cinema Exposed (EYE de Amsterdam, 2012).

La nómina de artistas que desde entonces han trabajado con las premisas del reciclaje cinematográfico es nutrida: los norteamericanos Craig Baldwin, Ernie Gehr y Bill Morrison, o los austríacos Norbert Pfaffenbichler, Martin Arnold o Peter Tscherkassky (continuadores en gran medida del camino transitado por Peter Kubelka), son algunos de sus representantes más insignes.

\section{Hollywood como referente}

Especialmente interesantes para los intereses de este trabajo resultan el alemán Mathias Muller (sobre todo en colaboración con Christoph Girardet) y el escocés Douglas Gordon quienes han utilizado el universo hollywoodiense como gran fuente de inspiración. El primero, desde sus inicios en el apropiacionismo cinematográfico a finales de la década de 1970, ha puesto en evidencia de manera reiterada las principales estrategias formales

$10 \mathrm{Al}$ igual que numerosos centros y festivales centraron su atención en el fenómeno con la realización de ciclos sobre cine y apropiacionismo. Entre ellos, el Stadtkino de Viena (1991), el festival de Lucerna (1991 y 1992), el IVAM de Valencia (1993), la Anthology Film Archives de Nueva York (1993) o el festival de Oberhausen (1996). 
que han regido el cine clásico. En una de sus piezas más conocidas, Home Stories (1990), pone en valor los mecanismos del sintagma melodramático y la construcción de su protagonista femenino a través de la concatenación de escenas procedentes de películas del género y que presentan una notable similitud formal. La acción que desarrollan las actrices en la imagen, su gestualidad, e incluso su fisonomía, ilustran de manera flagrante la extrema codificación del cuerpo cinematográfico hollywoodiense durante el studio system. Actrices como Shelley Winters, Grace Kelly o Tippi Hedren aparecen en la imagen abriendo y cerrando puertas, encendiendo las luces de las habitaciones, mirando a través de las ventanas, cerrando cortinas, levantándose de la cama y, sobre todo, expresando diferentes grados de emoción (de la preocupación a la curiosidad, pasando por el temor). Es a partir de esta dialéctica (alteridad de las protagonistas frente a la similitud de las fórmulas actorales y los cánones clásicos del género representado) como Müller deconstruye los estereotipos dominantes del film clásico hollywoodiense al que alude.

En la misma dirección pueden entenderse obras como Phoenix Tapes (1999), realizada con Christoph Girardet. La videoinstalación concentra en menos de una hora gran parte del imaginario temático y visual del cine de Alfred Hitchcock; los objetos, los espacios, los planos de detalle, etc., que adquieren esa reconocida densidad en manos del cineasta británico, se superponen en la pantalla bajo nuevos ritmos y acordes que alteran el sentido original. Más tarde, en Kristall (2006), vuelven sobre una de las fórmulas genéricas más queridas por los artistas: el melodrama. Y para ello, se interrogan sobre uno de los principales operadores formales del género: el espejo, superficie especular que, atravesando la cinematografía de Douglas Sirk o Vincent Minelli, da forma al desdoblamiento y quiebre que funda a los protagonistas melodramáticos. ${ }^{11}$

11 Al respecto, una vuelta de tuerca es operada en Play (2003), que desplaza el centro de atención desde el star system hollywoodiense al espectador cinematográfico, sujeto situado dentro de la historia. En la pantalla, en un cuidado montaje rítmico, se suceden por corte diversos planos del público que aplaude, encuadres que proceden de películas de formatos, tecnologías y temáticas tan dispares como Una noche en la ópera (A Night at the Opera, Sam Wood 1935), Ser o no ser (To Be or Not to Be, Ernst Lubitsch, 1942), Una estrella ha nacido (A Star is Born, George Cukor, 1954), El hombre que sabía demasiado (The Man Who Knew Too Much, Alfred Hitchcock, 1956), etc. 
Mayor relevancia adquiere Douglas Gordon por su reiterado interés en desbordar la bidimensionalidad del lienzo cinematográfico: el artista escocés no solo reutiliza material de insignes películas, sino que lo proyecta en superficies que se abren a la tridimensionalidad del espacio expositivo. Tal es el caso de Through a Looking Glass (1999), videoinstalación en la que contrapone dos grandes pantallas que escenifican el breve monólogo de Travis Bickle de Taxi Driver (Martin Scorsese, 1978). En esta escena, el inquietante personaje interpretado por Robert de Niro se pregunta a sí mismo obsesivamente "Are you talking to me?" delante de un espejo. Sumido en el ensimismamiento del esquizoide, Travis repite una y otra vez los gestos que le permitirán sacar la pistola que guarda bajo el gabán. Dando forma así a la perturbada dualidad del personaje, Gordon enfrenta de manera especular las dos pantallas donde se repite en bucle el diálogo esquizoide. Y aunque las dos proyecciones comienzan de manera sincronizada, la leve distorsión temporal entre las dos imágenes hace que poco a poco vayan perdiendo cohesión, haciendo más patente aún si cabe la fractura que habita la mente del protagonista. Travis contra Travis, o la conversación mise en abyme de un sujeto desdoblado, leitmotiv que atraviesa longitudinalmente la cinematografía de Scorsese: desde Taxi Driver a Shutter Island (2010), pasando por El aviador (The Aviator, 2004).

No obstante, la obra que lanzó internacionalmente a Gordon fue 24 Hour Psycho (1993), que consiste en la proyección en una pantalla, por las dos caras y sin sonido, de la famosa Psicosis, de Alfred Hitchcock (Psycho, 1960). ${ }^{12}$ El procedimiento a la hora de realizar la pieza fue sorprendentemente sencillo. Gordon compró en una tienda un VHS del film, y utilizó un aparato de video capaz de ralentizar la imagen hasta el límite mismo de la percepción de movimiento: frente a los 24 fotogramas por segundo de la película original, 24 Hour Psycho se proyecta en silencio a 1.8 fotogramas por segundo aproximadamente. Llamativa afrenta al dictum godardiano: si el cine es la verdad a 24 fotogramas por segundo, la pieza de Gordon atenta

12 No es el único trabajo de Gordon que interroga al maestro del suspense. Vértigo (1958) dio pie a la instalación Feature (1999). Trabajando en este caso sobre el sonido, Gordon rodó el concierto de la banda sonora interpretada por la orquesta de la Ópera de París, jugando con el montaje en un sentido hitchockiano. En el suelo, un pequeño monitor proyectaba la película sin sonido como mero recordatorio. 
drásticamente contra la verdad hitchcockiana. Nada queda aquí de la magistral capacidad del cineasta británico para atrapar al espectador; la dilatación ad infinitum de los planos invalida cualquier posibilidad de sobresalto, cualquier posibilidad de suspense. Sirva como ejemplo la escena de la ducha y el asesinato de la indefensa Marion Crane a manos, supuestamente, de la perturbada madre de Norman Bates. Reconocida unánimemente por el virtuosismo de la planificación y la aceleración vertiginosa del montaje (en apenas 3 min más de 50 planos), esta escena se expande hasta los 10 min en la pieza de Gordon.

La drástica ralentización que acontece tanto en esta escena como en la película en su conjunto emplazan al espectador de la instalación ante una experiencia sustancialmente distinta de la de la sala cinematográfica: el visionado de la película a su cadencia estándar lo interpela de otra manera que ante la velocidad que propone Gordon. Por no hablar de la movilidad del espectador en el espacio expositivo frente a su quietud en el espacio cinematográfico. Las características del relato hitchcockiano y su construcción narrativa pierden así toda relevancia en detrimento de la profusa e inabarcable exhibición de sus detalles visuales. La ligazón de las escenas y las secuencias y las dinámicas reactivas que determinan la implacable causalidad de la trama desaparecen detrás del poro de la imagen: de la perturbada y amenazadora presencia de Norman Bates, de la petrificada mirada de Marion sobre el suelo de la ducha o del descuelgue de las anillas que señala, metafóricamente, el fin de los latidos del corazón de la hasta entonces protagonista. Despojadas del peso narrativo, se convierten en imágenes que absorben la mirada del espectador, que lo abisman en su interior como ficcionalizara Don DeLillo (2010), por medio de uno de sus personajes, en su novela Punto Omega (2013): ${ }^{13}$

Hay que fijarse mucho para ver lo que ocurre delante de uno. Cuesta trabajo, supone un abnegado esfuerzo, ver lo que está uno mirando. Era algo que lo tenía hipnotizado, las profundidades posibles en la

13 Aunque el nombre de la instalación de Gordon no aparece explícitamente en la novela, como señala Eivind Rosaak (2014, p. 93), las referencias a esta son más que evidentes. Indicar que la pieza de Gordon se proyectó todos los días durante tres meses en el MoMA de Nueva York, en 2006, y el citado personaje visita en la novela una videoinstalación en una galería de Nueva York en la que se proyectan durante 24 horas imágenes de Psicosis. 
desaceleración del movimiento, las cosas que ver, la profundidad de las cosas tan fácil de no ser percibida en la costumbre superficial de ver. (pp. 21, 22)

La radicalidad expositiva de 24 Hour Psycho y sus consecuencias espectatoriales pueden ser puestas en relación con The Clock (2010), pieza realizada por Christian Marclay que radicaliza, en no pocos aspectos, su anterior Telephones (1995), y que fue merecedora del León de Oro en la 54 edición de la Bienal de Venecia (2011). Las similitudes y las diferencias con la obra de Gordon se hacen evidentes. La duración de la pieza de Marclay es, al igual que la anterior, de 24 horas; temporalidad que atenta, abiertamente, contra la propia experiencia espectatorial. La principal diferencia, sin embargo, radica en que The Clock no destruye la verosimilitud narrativa originada por la ralentización de la imagen, sino que se constituye a partir de la yuxtaposición de miles de fragmentos audiovisuales televisivos y cinematográficos que, en la reiterada mostración de fuentes de información temporal (fundamentalmente relojes), consiguen establecer una eficaz homología entre el tiempo diegético y el tiempo extradiegético, o lo que es lo mismo, entre el tiempo del universo ficcional que desfila en la pantalla y el tiempo del universo real del espectador. Si aquella, por tanto, suspende la mirada en la fruición de la imagen, esta, por el contrario, obliga a su toma de conciencia a través de la confrontación con las acciones que se despliegan en la pantalla.

\section{Más allá de Hollywood}

Pero no solo esa fábrica de sueños que nutrió el imaginario occidental de las décadas centrales del siglo XX ha operado como interlocutor del arte. Tan cerca y tan lejos de las propuestas aquí esbozadas se sitúan aquellos cineastas/artistas cuyo trabajo se mira en el reflejo anónimo del cine amateur y familiar. ${ }^{14}$ Tal es el caso de Alan Berliner, Yervant Gianikian y Angela Ricci o Péter Forgács, cuya obra gira en torno a las tensiones existentes entre historia(s) versus Historia, a partir de la noción de Centroeuropa (Mitteleuropa), más concretamente, de los procesos históricos que sentaron las bases del horror nazi y la Segunda Guerra Mundial. En La familia Bartos (The

14 Para una profundización sobre el cine amateur, familiar, doméstico, etc., consúltese Cuevas (2010). 
Bartos Family, 1988), película que forma parte de la serie Hungría Privada (Private Hungary) que realizó entre 1988 y 1997, a partir del metraje filmado por el mayor de los tres hermanos, Zoltán Bartos, Péter Forgács pone en escena la vida cotidiana de los miembros de una rica familia de Budapest antes de ser enviados a los campos de concentración; la diferencia de saberes entre el espectador y los personajes, ajenos a su futuro inmediato, confieren a la imagen una dolorosa profundidad. A su vez, en forma de díptico, Éxodo por el Danubio (The Danube Exodus, 1998), recoge, por un lado, el trayecto de dos barcos que trasportaron 900 judíos eslovacos de Bratislava a través del Danubio; y por otro, el mismo camino de vuelta con los alemanes evacuados de Estonia, Lituania y Letonia después de la ocupación de las tropas soviéticas. $\mathrm{O}$ en El perro negro: historias de la guerra civil española (El perro negro: Stories from the Spanish Civil War, 2005), Forgács ofrece una de las más originales y fascinantes propuestas estéticas sobre la guerra civil española. A partir de la fértil confrontación entre los conocidos documentos audiovisuales de la fratricida contienda y los metrajes amateurs y familiares de Ernesto Noriega, estudiante madrileño aficionado al cine, así como de los de Joan Salvans, miembro de una importante familia del tejido industrial textil catalán que fue asesinado en los preliminares de la contienda, el cineasta húngaro construye un poderoso discurso fílmico sobre nuestro pasado más reciente que fue objeto de no pocas controversias antes incluso de su presentación pública. ${ }^{15}$

\section{Remake y posmodernidad}

$\mathrm{Al}$ margen de poner en valor ese cine found footage que ha sido convenientemente analizado, merece la pena prestar atención a una tendencia contemporánea menos visible, pero que, en virtud de la particular relación que establecen las obras traídas a colación (imagen apropiacionista respecto de la imagen apropiada), se emplazan en el corazón mismo de la condición de posibilidad de la experiencia estética y, lo que es más importante aún, cuestionan los principios sobre los que se ha asentado tradicionalmente el culto

15 El sindicato anarquista CNT (Confederación Nacional de Trabajadores), que tenía los derechos de algunas de sus imágenes, dificultó su distribución por discrepancias con el resultado del trabajo. Según Arcadi Espada (2006), prohibieron su proyección en la pequeña pantalla. Según datos del MMinisterio de Educación, Cultura y Deportes, El perro negro se estrenó el 26 de abril de 2007 en la Filmoteca de Cataluña y tuvo 91 espectadores. 
de la imagen. En pocas palabras, el diálogo con obras cinematográficas referentes que proponen artistas, como el canadiense Mark Lewis, los franceses Olivier Bardin y Pierre Huygue o el lituano Deimantas Narkevičius, debe comprenderse como un ejercicio diferenciado de aquel que recicla un material fílmico precedente.

En primer lugar, y antes que nada, conviene dejar claro que nos encontramos casi en las antípodas de las estrategias habituales de remaking cinematográfico, de esa concepción industrial para la que, en palabras de Constantine Verevis,

los remakes son tenidos en cuenta de forma insistente a la hora de proporcionar modelos adecuados, como de una garantía financiera se tratase, para el desarrollo de proyectos de estudio. En un contexto comercial, los remakes son "vendidos de antemano" a su audiencia porque se asume que los espectadores ya tienen una experiencia previa, 0 al menos tienen una "imagen narrativa", de la historia original - de una película previa o de la fuente literaria - antes de involucrarse en su nueva forma de ser narrado. $(2006$, p. 3)

En segundo lugar, no puede obviarse el fondo de semejanza que mantienen estas propuestas respecto del cine apropiacionista. No en vano comparten un mismo principio de reordenación y construcción de nuevos sentidos a partir de unas imágenes de partida, esencia discursiva del metraje encontrado, como señalara Thomas Elsaesser:

Las películas de found footage no solo combinan material, sino que también componen ese mismo material para convertirlo en un nuevo todo, en una nueva unidad coherente. Por consiguiente, los films de found footage tienden a crear nuevos contextos en los que se reubican las imágenes posibilitando nuevas asociaciones de significantes. (2015, p. 120)

\section{Del remake como práctica dialógica}

Nos seguimos encontrando, pues, en los territorios de la poética dialógica descrita por Mijail Bajtin. Sin embargo, si tanto Gordon como Müller o Forgács deconstruyen mayoritariamente la imagen cinematográfica desde su interior (reciclan y reutilizan el material fílmico ya existente), Mark 
Lewis, Pierre Huygue o Deimantas Narkevičius suelen hacerlo desde el exterior, situándose en el borde mismo del discurso al que citan: las imágenes referentes son explícitamente interpeladas como imágenes objeto a partir de las cuales desplegar una reflexión de orden metartístico. ${ }^{16}$ Es de la propia imagen y de su condición original de lo que se está hablando. Y aún más, se pone en valor la implicación del espectador en cuanto agente que intenta clausurar un sentido que no se deja clausurar, sujeto escindido entre dos discursos audiovisuales que lo interpelan al unísono pero de manera diferente: uno en presencia (la imagen referida) y otro en ausencia (la imagen referente).

Así, por ejemplo, Mark Lewis recrea algunas escenas de El fotógrafo del miedo (Peeping Tom, Michael Powell, 1960) en su pieza Peeping Tom (2000) o reconstruye el famoso plano secuencia que da comienzo a Sed de mal (Touch of Evil, Orson Welles, 1958), pero invirtiendo la proyección en Upside Down Touch of Evil (1997). Mayor relevancia al respecto adquiere no obstante la obra de Pierre Huygue, cuya trayectoria artística, como en el proyecto No Ghost Just a Shell que inició junto con Philippe Parreno en 1999 tras comprar los derechos de un personaje manga japonés, ha girado en torno a la noción de originalidad en numerosas ocasiones. ${ }^{17}$ Así, en 1995, realizó Remake, minuciosa reelaboración de La ventana indiscreta (Rear Window, Hitchcok, 1954) a partir de una escenografía casera y unos actores amateurs. La dialéctica que se establece entre la idéntica estructura narrativa y formal (mismo encuadre, mismo diálogo, mismo movimiento de cámara), así como el carácter artesanal de la puesta en escena y la utilización de actores amateurs que despliegan su corporeidad en un espacio netamente diferenciado de la elaborada escenografía original en estudio (Remake fue grabado en un apartamento en construcción de un barrio popular), establecen un fuerte contraste respecto del film hitch-

16 Incluso Matthias Müller ha transitado esta vía en Alpsee (1994), donde construyó un ensayo de tintes autobiográficos sobre el tránsito de la infancia a la madurez, aludiendo formalmente a la estética del melodrama (hollywoodiense en general y de Douglas Sirk en concreto).

17 Pero también ha trabajado Pierre Huygue con material apropiado, como en Versions Multiples (Atlantic-AtlantikAtlantis, 1929) (1997), donde proyecta el film Atlantic en tres versiones diferentes (francés, inglés y alemán). Las diferencias que existen, que no son solo idiomáticas, desvirtúan la propia noción de versión original. ¿Cuál es la verdadera y cuáles las falsas? Y aún más: ¿se puede hablar de verdadera y falsas? 
cockiano: La ventana indiscreta es expuesta a la luz pública como un artefacto discursivo del que pueden contemplarse sus fundamentos retóricos. Pero aún más, como apuntó Nicolás Bourriaud a propósito de Remake, en la repetición plano por plano de la película, "se representa algo distinto de lo que se trataba en la obra original. Se muestra el tiempo que ha pasado, pero sobre todo se manifiesta una capacidad para moverse entre los signos, para habitarlos" (2009, p. 65).

Es precisamente sobre esa capacidad para habitar los signos cinematográficos - y de hacerlo, además, a partir del paso del tiempo- que el artista ha construido algunos de sus trabajos posteriores como Les incivils (1996) o L'Ellipse (1998). El primero se erige como una explícita incursión en el universo fílmico de Pier Paolo Pasolini mediante la convocación de Pajaritos y pajarracos (Uccellacci e uccellini, 1966). En el film, un padre, Innocenti Totò (interpretado por el reconocido cómico italiano Totò), y su hijo, Innocenti Ninetto (interpretado por Ninetto Davoli, actor fetiche del cineasta italiano), deambulan por los alrededores de una ciudad cuando, de repente, son interpelados por un cuervo negro con el que entablan una conversación de marcado tono sarcástico. Tal es el material de partida que reinterpreta el artista francés: Huygue recurre a Davoli que vuelve a transitar el mismo camino treinta años después. No obstante, además de la notable ausencia de Totò, Les incivils saca al film referente de sus contornos narrativos mediante la intercalación de algunos parajes que no aparecían en Pajaritos y pajarracos; parajes que están relacionados directamente con las experiencias vitales del propio Pasolini, caso de la playa de Ostia donde el cineasta fue asesinado en 1975.

En su posterior trabajo, L'Ellipse, Huygue profundiza en las estrategias operadas en Les incivils, añadiendo, al distanciamiento temporal, un distanciamiento espacial. No en vano, transcurridos veinte años, Bruno Ganz interpreta de nuevo a Jonathan Zimmerman, uno de los protagonistas de El amigo americano (Der Amerikanische Freund, Win Wenders, 1977). Pero, en este caso, el actor se mete en la piel del fabricante de marcos para "rellenar" una escena rodada por Win Wenders que desapareció de la versión final. La instalación, constituida por tres pantallas simultáneas, proyecta en el 
centro el plano secuencia en el que el Bruno Ganz actual atraviesa un puente por el Sena. El recorrido, que dura aproximadamente $8 \mathrm{~min}$, es acompañado en los laterales por las escenas que lo anteceden y suceden en el film original (Ganz espera en un apartamento la llamada que confirme su enfermedad terminal y enlaza con la oferta de empleo criminal en otro apartamento situado en la orilla contraria).

La puesta en simultaneidad de la imagen documental junto con las otras ficcionales y los manifiestos contrastes que se inscriben entre los dos tipos de imágenes (edad avanzada de Ganz, carácter videográfico de la grabación actual) radicalizan el descentramiento narrativo que vertebraba Les incivils a la vez que manifiestan la radical irrupción de lo real en el universo ficcional del film de Wenders, eje central de la poética de Pierre Huygue que asume íntegramente el artista lituano Deimantas Narkevičius, quien elaboró una profunda reflexión sobre la extinta Unión Soviética en su obra Revisiting Solaris (2007). Cuarenta años después del legendario film de Andrei Tarkovsky, basado en la novela del conocido escritor de ciencia ficción Stanislaw Lem, Deimantas Narkevičius convoca de nuevo a su actor principal, Donatas Banionis, para que vuelva a meterse en la piel de Chris Kelvin, el astronauta que en el film de Tarkovsky recibía la perturbadora visita de un "ente" que era idéntico a su esposa muerta. La revisitación que propone el artista, no obstante, no se sitúa en el marco narrativo desplegado por el cineasta ruso, sino que lo supera al situarse en el último capítulo del novelista que no fue incluido por Tarkovsky, y en el que el protagonista reflexionaba sobre su corta estancia en el extraño planeta. Película referente y videoinstalación resultante, establecen así un diálogo abierto en el que el material narrativo inicial se ve desbordado en su interior (marco narrativo posterior al de la película) y en su exterior (la historia del actor y su condición de ciudadano ruso que vivió el hundimiento del sistema soviético).

Y aún podría señalarse el complejo artificio que Olivier Bardin elabora a partir de la película Le camion (1977), de Marguerite Duras, en su pieza homónima de 2001. Al igual que en Remake, de Huyghe, el artista reelabora el material de partida mediante su recreación por parte de dos nuevos actores. A diferencia de aquel, sin embargo, el vídeo de Olivier Bardin 
realiza también ciertas operaciones sobre el texto de origen que terminan por otorgarle un mayor espesor semántico. Por un lado, el texto íntegro de la versión original es leído por el personaje masculino a diferencia de la anterior, en la que Marguerite Duras y Gérard Depardieu conversaban a propósito de una película nunca filmada. Por otro lado, acontece un proceso de condensación y reducción de los elementos formales del film referente que ahondan en la paradójica relevancia que adquiere la palabra en la nueva obra. No en vano, al silencio del personaje femenino en la nueva versión, hay que añadir también la supresión del sonido en la proyección vídeo: al texto solo se accede mediante su lectura en los subtítulos.

\section{A modo de conclusión}

El trabajo de estos últimos artistas resulta especialmente revelador de las estrategias discursivas de aquellas imágenes contemporáneas que convocan a otras desde la exterioridad, conversación que pone de relieve con nitidez la relación que se establece entre imagen referente e imagen referida, entre original y su doble: no se trata tanto de una reproducción exacta del original como de una imagen intencionadamente distante. Nos encontramos, por tanto, de lleno en la clásica diferencia establecida por Platón en El sofista entre la copia y la fantasmagoría, entre aquella imagen que reproduce exactamente las proporciones del modelo y aquella que se distancia de la imitación verdadera para hacerlo en su apariencia. Si la copia es una imagen dotada de semejanza, el simulacro sería una imagen sin semejanza, imagen que se construye de hecho desde su condición disímil. Pero si en la poética platónica el simulacro es relegado a las tinieblas de lo falso, Deleuze lo recupera otorgándole una potencia positiva, una capacidad para negar "el original, la copia, el modelo y la reproducción” (2005, p. 305).

Desde esta perspectiva, por tanto, el simulacro no debe ser considerado como una copia degradada, artificial. Antes bien, se trata de un doble que cuestiona las distinciones y los conceptos de veracidad-falsedad que fecundan toda representación. Ya no existe diferencia entre verdadero y falso, entre un original convertido en el centro del sistema y unas copias que intentan parecérsele. Frente al icono copia y la semejanza del remake hollywoodiense, se sitúa el simulacro y la diferencia, repetición con variación 
que establece una distancia entre las dos imágenes. ${ }^{18}$ He ahí, tal vez, donde reside el verdadero gesto político de estas propuestas: la conciencia de unas imágenes que, en última instancia, se reconocen incapaces de situarse en el centro alrededor del cual se articule sistema alguno.

En definitiva, desde que el arte de principios del siglo XX desistiera de los postulados de una creación ex nihilo para operar con materiales que ya circulaban en la sociedad, el cruce de caminos estético y la migración de las imágenes de un medio a otro se ha convertido en una dominante del sistema artístico actual. Y más que la publicidad o la televisión, medios objeto utilizados por numerosos artistas para desvelar los cimientos de la ideología dominante y denunciar la enajenación del sujeto contemporáneo, el discurso artístico ha utilizado - y utiliza — como interlocutor privilegiado la imagen cinematográfica, acaso como espejo incierto en el que proyectar sus inquietudes desde la otredad. Por un lado, se encuentran aquellos creadores que se han apropiado en sentido literal del material cinematográfico para deconstruirlo en una nueva unidad que recompone el conjunto de partida (de Joseph Cornell a Douglas Gordon pasando por Bruce Conner). Por otro lado, están aquellos artistas que han dialogado con la imagen cinematográfica desde el exterior: las propuestas de Mark Lewis, Pierre Huygue o Deimantas Narkevičius obligan a una reflexión audiovisual de enorme calado que cuestiona los conceptos de originalidad y copia, elementos esenciales tanto del devenir estético como de la experiencia estética referida a un sujeto. En ambos casos, no obstante, puede llegarse a una misma conclusión: si la imagen artística en la contemporaneidad se caracteriza por su condición fantasmal y errante, como señaló José Luis Brea, es desde luego el espíritu cinematográfico lo que parece animarla.

\section{Referencias}

Arthur, P. (1999). The status of found footage. Spectator-The University of Southern California Journal of Film and Television, 20(1), 57-69.

18 Se remarca así, de manera más acentuada, aún que en el found footage una estilización de tipo paródico por la que "las intenciones del lenguaje que representa no coinciden con las intenciones del lenguaje representado, se le oponen, no representan el universo objetual real con la ayuda del lenguaje representado, como punto de vista productivo, sino por medio de su desenmascaramiento y destrucción” (Bajtin, 1989, pp. 179-180). 
Baigorri, L. (2004). Vídeo: primera etapa: el vídeo en el contexto social y artístico de los años 60/70. Asociación Cultural Brumaria.

Bajtin, M. (1987). La cultura popular en la Edad Media y en el Renacimiento: el contexto de François Rabelais. Buenos Aires: Alianza Editorial.

Bajtin, M. (1989). Teoría y estética de la novela. Madrid: Taurus.

Barbancho, J.-R. (ed.) (2009). Remakes: vídeo sobre cine. Gijón: Fundación Municipal de Cultura y Educación/Universidad Popular del Ayuntamiento de Gijón.

Basilico, S. (ed.) (2004). Cut: Film as found object in contemporary video. Miwaukee: Milwaukee Art Museum.

Bonet, E. (ed.) (1993). Desmontaje: film/vídeo/apropiación/reciclaje. Valencia: IVAM.

Bourriaud, N. (2009). Post-producción. Buenos Aires: Adriana Hidalgo Editora.

Brea, J. L. (2014). Las tres eras de la imagen. Madrid: Akal.

Burch, N. (1987). El tragaluz del infinito. Madrid: Cátedra.

Bürger, P. (1997). Teoría de la vanguardia. Barcelona: Península.

Burguelin, P. (1970). Análisis de Michel Foucault. Buenos Aires: Tiempo Contemporáneo.

Cuevas, E. (2010). La casa abierta: el cine doméstico y sus reciclajes contemporáneos. Madrid: Ocho y Medio.

Deleuze, G. (2005). La lógica del sentido. Barcelona: Paidós.

Delillo, D. (2010). Punto omega. Barcelona: Seix Barral. 
Dubois, P. (2011). La Question vidéo: entre cinéma et art contemporain. Crisnée: Yellow Now.

Dubois, P., Melon, M. E. y Dubois, C. (1988). Cinéma et vidéo: interpénétrations. Communications, 48(1), 267-321.

Elsaesser, T. (2015). La ética de la apropiación: Found footage, entre el archivo e internet. Found Footage Magazine, 1, 119-123.

Evans, D. (ed.) (2009). Appropriation. Londres: Whitechapel/Mass MIT Press.

Fernández Guerra, V. (2014). Filmar pensando, pensar filmando: trabajo colectivo, autoría y documental en Los Materiales de Los Hijos. En Actas VI Congreso Internacional Latino de Comunicación Social. San Cristóbal de La Laguna, España: Universidad de La Laguna.

Foucault, M. (2006). La arqueología del saber. México: Siglo XXI.

Guardiola, I. (2015). Found footage y televisión: imágenes que relampaguean en el instante de un peligro. Found Footage Magazine, 1, 131-135.

Kuspit, D. (1993). The cult of the Avant-garde artist. Nueva York: Cambridge University Press.

Marchan Fiz, S. (1994). Del arte objetual al arte del concepto: epílogo sobre la sensibilidad posmoderna. Madrid: Akal.

Mitry, J. (1974). Historia del cine experimental. Valencia: Fernando Torres.

Monterde, J. E. (1991). Los surrealistas como espectadores. En Surrealistas, surrealismo y cinema (pp.49-79). Barcelona: Fundación La Caixa.

Païni, D. (2002). Le temps exposé: le cinéma de la salle au Musée. París: Cahiers du Cinéma.

Prada, J. M. (2001). La apropiación posmoderna. Madrid: Fundamentos. 
Sánchez-Biosca, V. (2004). Cine y vanguardias artísticas: conflictos, encuentros, fronteras. Madrid: Paidós.

Rosaak, E. (2014). The delay in the system: Why Douglas Gordon Needed Alfred Hitchcock. Millennium Film Journal, 59, 86-94.

Royoux, J.-C. (2001). Remaking cinema: les nouvelles stratégies du remake et l'invention du cinéma d'exposition. En Reproductibilité et irreproductibilité de l'œuvre d'art (pp. 215-229). Bruselas: La lettre volée.

Vancheri,L. (2009). Cinémas contemporains: du filmál'installation. Lyon: Aléas.

Verevis, C. (2006). Film remakes. Edimburgo: Edinburgh University Press.

Wees, W. (1993). Recycled images: The Art and politics of found footage films. Nueva York: Anthology Film Archives.

Welchman, J. (2003). Art after appropriation: Essays on art in the 1990s. Nueva York: Routledge.

Weinrichter, A. (1998). Propuestas al margen: falso documental y metraje encontrado. Archivos de la Filmoteca, 30, 25-32.

Weinrichter, A. (2009). Metraje encontrado: la apropiación en el cine documental y experimental. Navarra: Festival Internacional de Cine Documental de Navarra.

Zryd, M. (2003). Found footage film as discursive metahistory: Craig Baldwin's Tribulation 99. The Moving Image, 3(2), 40-61. doi: 10.1353/mov.2003.0039. 